\title{
S100A4/Nonmuscle Myosin IIA/p53 Axis Contributes to Aggressive Features in Ovarian High-Grade Serous Carcinoma
}

Ai Hiruta, Yasuko Oguri, Ako Yokoi, Toshihide Matsumoto, Yusuke Oda, Mikihisa Tomohiro, Miki Hashimura, Zesong Jiang, Masataka Tochimoto, Mayu Nakagawa, and Makoto Saegusa

From the Department of Pathology, Kitasato University School of Medicine, Sagamihara, Japan

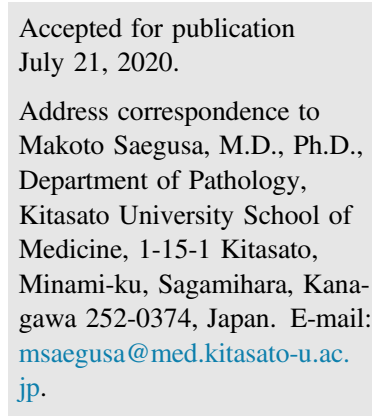

\begin{abstract}
S100A4 is a small calcium-binding protein that exerts its biological functions by interacting with nonmuscle myosin IIA (NMIIA) and p53. Although S100A4 promotes metastasis in several tumors, little is known about its involvement in the progression of ovarian high-grade serous carcinomas (HGSCs). Herein, we focused on functional roles of the S100A4/NMIIA/p53 axis in these tumors. In HGSC cell lines harboring mutant p53, knockdown (KD) of S100A4 reduced the expression of several epithelialmesenchymal transition/cancer stem cell markers and the $\mathrm{ALDH} 1^{\text {high }}$ population, consistent with an inhibition of stemness features. S100A4-KD also increased apoptosis, decreased cell proliferation, and accelerated cell mobility. This was accompanied by increased Snail expression, which, in turn, was likely due to loss of p53 function. In contrast, specific inhibition of NMIIA by blebbistatin induced phenotypes that - with the exception of cell proliferation and mobility - were opposite to those observed in S100A4-KD cells. In clinical samples, cytoplasmic and/or nuclear interactions between S100A4, NMIIA, and mutant p53 were observed. In addition, high expression of S100A4, but not NMIIA or p53, was a significant and independent unfavorable prognostic factor in HGSC patients. These findings suggest that, via its interaction with NMIIA and p53, overexpressed S100A4 may induce epithelial-mesenchymal transition/cancer stem cell properties in HGSC and elicit several other tumor-associated phenotypes. (Am J Pathol 2020, 190: 2304-2316; https://doi.org/10.1016/j.ajpath.2020.07.014)
\end{abstract}

Ovarian high-grade serous carcinoma (HGSC) is the most common type of ovarian carcinoma and is the leading cause of gynecologic malignancy-related deaths in East Asia., The ovaries are in a relatively inaccessible location, and ovarian carcinoma patients often lack symptoms during the early stages. As a result, almost $75 \%$ of patients already have advanced stage disease at diagnosis, which is characterized by metastasis to the peritoneal cavity. ${ }^{3}$ The 5 -year survival rate in patients diagnosed at the early stage is $>70 \%$, but this ratio declines to $35 \%$ in patients with advanced disease. ${ }^{4}$ Approximately $80 \%$ of advanced stage patients have residual disease after surgery and receive frontline platinum-based combination chemotherapy. However, tumor resistance to the therapy increases the risk of recurrence, resulting in a high mortality rate. ${ }^{5}$ Therefore, it is essential to identify biomarkers that can predict patient responses to available treatments or that can be used for prognosis in HGSC.

The S100 family consists of 21 acidic $\mathrm{Ca}^{2+}$-binding proteins, which are characterized by two EF-hand $\mathrm{Ca}^{2+}$ binding motifs that function as sensors of both intracellular $\mathrm{Ca}^{2+}$ and extracellular factors. ${ }^{6-8}$ The S100 members exhibit a high degree of structural similarity but are not functionally interchangeable. ${ }^{9}$ Of these, S100A4 (alias metastasis-associated protein ${ }^{10}$ ) is frequently up-regulated in a variety of human malignancies, leading to oncogenic transformation, angiogenesis, mobility, and metastasis of tumor cells. ${ }^{6,10,11}$ S100A4 possesses no enzymatic activity;

Supported by Japan Society for the Promotion of Science KAKENHI grant 17K08703 (M.S.).

Disclosures: None declared. 
instead, it exerts its effects by interacting with and modulating the activity of other proteins, such as $\mathrm{p} 53$, nonmuscle myosin IIA (NMIIA), and Annexin 2. ${ }^{12,13}$

NMII is a master regulator of cell morphology, with a role in several essential cellular processes. ${ }^{14,15}$ There are three NMII isoforms (A, B, and C) that consist of different NMII heavy chains sharing essential and regulatory light chains. NMIIA elicits tumor invasion and metastasis via activation of cell migration, adhesion, protrusion formation, loss of cell polarity, and suppression of apoptosis. ${ }^{14,15}$ Interestingly, the tumor suppressor capability of wild-type p53 (p53wt) is dependent on functional NMIIA, whereas the invasive phenotype induced by high-risk mutant p53 (p53mt) is NMIIA independent in head and neck carcinomas. ${ }^{16}$

Our previous study demonstrated that an S100A4/ NMIIA-related signaling cascade triggers divergent sarcomatous differentiation from carcinomatous components in uterine carcinosarcomas. ${ }^{17}$ On the basis of this result, we designed the current study to test whether alterations in the S100A4/NMIIA/p53 axis might also determine the phenotypic characteristics of HGSC. To examine this, we investigated associations between S100A4, NMIIA, and p53 expression and mutational status in both clinical cases and tumor cell lines.

\section{Materials and Methods}

\section{Plasmids, Cell Lines, and Reagents}

S100A4-specific shRNA, pGL-3B-(-1109/36) Snail luc, and WWP ( $p 21^{\text {wafl }}$ promoter) luc were used, as described previously. ${ }^{17-19}$ Three HGSC cell lines, OVSAHO, OVKATE, and OVCAR-3, were obtained from the National Institute of Biomedical Innovation (Osaka, Japan) or ATCC (Manassas, VA). Two endometrial carcinoma (Em Ca) cell lines, Ishikawa and Hec6 cells, were also used, as described previously. ${ }^{17-19}$ S100A4-shRNA or empty vector (control) were transfected into OVCAR-3 cells with high S100A4 expression (Supplemental Figure S1A), and the S100A4knockdown (S100A4-KD) cells, as well as the control cells, were established as described previously. ${ }^{17}$

Cisplatin (CDDP; P4394) and Nutlin-3A (N6287) were purchased from Sigma-Aldrich Chemicals (St. Louis, MO), and blebbistatin (B592500) was from Toronto Research Chemicals (North York, ON, Canada).

\section{Antibodies}

Anti-Rb (catalog number 554136), anti-N-cadherin (catalog number 610920), anti-aldehyde dehydrogenase (ALDH) 1 (catalog number 611194), anti-X-linked inhibitor of apoptosis protein (catalog number 610762), anti-bax (catalog number 610982), and anti-p27 ${ }^{\mathrm{kip} 1}$ antibodies (catalog number 610242) were purchased from BD Biosciences (San Jose, CA). Anti-S100A4 (rabbit; catalog number ab124805), anti-Smad2 (catalog number ab40855), anti-phosphorylated Smad2 at serine255 (catalog number ab188334), anti-Sox2 (catalog number ab97959), antiNestin (catalog number ab22035), anti-Snail (catalog number ab180714), and anti-Twist1 antibodies (catalog number ab50887) were obtained from Abcam (Cambridge, MA). Anti-phosphorylated $\mathrm{Rb}$ at serine807/811 (catalog number 9308), anti-vimentin (catalog number 5741), anti-cleaved caspase-3 (catalog number 9664), and anti-Slug antibodies (catalog number 9585) were from Cell Signaling (Danvers, MA). Anti-p21 ${ }^{\text {waf1 }}$ (catalog number M7202), anti-cyclin D1 (catalog number M3642), and anti-p53 antibodies (catalog number M7001) were purchased from Dako (Copenhagen, Denmark). Anti-ZEB1 (catalog number HPA027524) and anti- $\beta$-actin antibodies (catalog number A5441) were obtained from Sigma-Aldrich Chemicals. Anti-NMIIA (catalog number 11128-1-AP) and antiS100A4 (mouse; catalog number 66489-1-Ig) were obtained from Proteintech (Rosemont, IL). Anti-E-cadherin (catalog number M106), anti-CD133 (catalog number 130092-395), anti-cyclin B1 (catalog number sc-752), and anti-cyclin A2 antibodies (catalog number NCL-CYCLIN A) were from Takara (Shiga, Japan), Miltenyi Biotechnology (Bergisch Gladbach, Germany), Santa Cruz Biotechnology (Dallas, TX), and Novocastra (Newcastle, UK), respectively.

\section{Transfection}

Transfection was performed using LipofectAMINE PLUS (Invitrogen, Carlsbad, CA), and luciferase activity was assayed as described previously. ${ }^{17-19}$

\section{RT-PCR}

cDNA was synthesized from $2 \mu \mathrm{g}$ of total RNA. Amplification of S100A4 mRNA by RT-PCR was performed in the exponential phase to allow comparison of cDNAs synthesized from identical reactions using specific primers. The primers used for the S100A4 and GAPDH genes have been described previously. ${ }^{17}$

\section{Western Blot Assay and Co-IP}

Total cellular proteins were isolated using radioimmunoprecipitation assay buffer $[20 \mathrm{mmol} / \mathrm{L}$ Tris- $\mathrm{HCl}(\mathrm{pH}$ 7.2), $1 \%$ Nonidet P-40, $0.5 \%$ sodium deoxycholate, and $0.1 \%$ SDS]. Aliquots of the proteins were resolved by SDSPAGE, transferred to membranes, and probed with primary antibodies, coupled with the ECL detection system (Amersham Pharmacia Biotechnology, Tokyo, Japan).

For co-immunoprecipitation (co-IP), cells were lysed with IP buffer $[10 \mathrm{mmol} / \mathrm{L}$ Tris- $\mathrm{HCl}(\mathrm{pH} 7.6), 100 \mathrm{mmol} / \mathrm{L} \mathrm{NaCl}$, and $10 \% \mathrm{NP}-40]$ in the presence of $1 \mathrm{mmol} / \mathrm{L} \mathrm{CaCl}$. Cell lysates were cleared and incubated with anti-S100A4, antiNMIIA, or p53 antibodies, followed by incubation with Protein G-Sepharose (Amersham Pharmacia Biotechnology). 
Western blot assay was subsequently performed with antiS100A4, anti-NMIIA, and anti-p53 antibodies.

\section{Flow Cytometry and the Aldefluor Assay}

Cells were fixed using $70 \%$ alcohol and stained with propidium iodide (Sigma) for cell cycle analysis. ALDH1 enzyme activity in viable cells was determined using a fluorogenic dye-based Aldefluor assay (Stem Cell Technologies, Grenoble, France), according to the manufacturer's instructions. The prepared cells were analyzed by flow cytometry using BD FACS Calibur (BD Biosciences) and CellQuest Pro software version 3.3 (BD Biosciences).

\section{Spheroid Assay}

Cells $\left(\times 10^{3}\right)$ were plated in low cell binding plates (Thermo Fisher Scientific, Yokohama, Japan) in a serum-free culture medium or Eagle's minimal essential medium with $10 \%$ bovine calf serum. Uniform spheroids with a minimum diameter of $50 \mu \mathrm{m}$ were counted approximately 2 weeks following plating.

\section{Cell Counting Kit-8 (CCK-8) Assay}

The quantitation of viable cells after CDDP or blebbistatin treatment was performed using a Cell Counting Kit- 8 (Dojindo Lab, Kumamoto, Japan), according to the manufacturer's instructions.

\section{Wound Healing Assay}

Cells were seeded into 24-well tissue culture plates and grown until almost confluent. After the cell monolayer formed, a wound was scratched with a sterile $200-\mu \mathrm{L}$ tip. The area of the wound was analyzed by ImageJ software version 1.41 (NIH, Bethesda, MD; http://imageJ.nih.gov/ij). Cell migration parameters were calculated in pixels to quantify wound closure.

\section{Migration Assay}

Cell migration was determined using 24-well transwell chambers with $8-\mu \mathrm{m}$ pore size (Corning, Corning, NY). The lower chamber was filled with medium containing $10 \%$ serum. Cells were suspended in the serum-free upper medium with or without blebbistatin and transferred into the upper chamber. After 24 hours, the number of cells stained by hematoxylin-eosin on the bottom surface of the polycarbonate membranes was counted visually using a light microscope.

\section{TCGA Data Analysis}

The Cancer Genome Atlas (TCGA) HGSC data set (395 cases) was used to annotate TP53 gene alterations. mRNA expression data (RNA Seq V2 PSEM) for S100A4 and
Myosin9 heavy chain (MYH9) (NMIIA) for 201 cases were extracted from cBioportal for Cancer Genomics (http:// www.cbioportal.org, last accessed March 4, 2020).

\section{Clinical Cases}

A total of 116 cases of ovarian serous carcinomas (including 108 HGSC and 8 ovarian low-grade serous carcinoma, surgically resected at Kitasato University Hospital in the period from 2006 to 2017) were selected from our patient records, according to the criteria of the 2014 World Health Organization classification. ${ }^{20}$ All patients underwent oophorectomy with or without hysterectomy. None of the patients had received chemotherapy or any other preoperative treatment, whereas most patients had received paclitaxel/carboplatin-based chemotherapy after surgical treatment. Of these, 79 cases showed complete resection of the tumors, whereas 25 cases had residual tumors after debulking surgery. All tissues were routinely fixed in $10 \%$ formalin and processed for embedding in paraffin wax. Approval for this study was given by the Ethics Committee of the Kitasato University School of Medicine (B16-10).

\section{Immunohistochemistry}

Immunohistochemistry (IHC) was performed using a combination of the microwave oven heating and polymer immunocomplex (Envision; Dako, Copenhagen, Denmark) methods, as described previously. ${ }^{17-19}$

For evaluation of IHC findings, scoring of nuclear/cytoplasmic immunoreactivity was performed, on the basis of the percentage of immunopositive cells and the immunointensity, with multiplication of values of the two parameters, as described previously. ${ }^{17-19}$

To evaluate the prognostic significance of S100A4, NMIIA, and p53 expression, the scores were divided into two categories (high and low) with the mean values as the cutoff in each category (Table 1). With regard to p53, cases that were completely negative for p53 immunoreactivity were categorized into the high p53 score group (score $=12$ ), because combining two IHC labeling patterns associated with p53 mutations $(0 \%$ and $60 \%$ to $100 \%$ positive cells) correctly identified a mutation in $94 \%$ of cases. ${ }^{21}$

\section{Proximity Ligation Assay}

The slides were heated in $10 \mathrm{mmol} / \mathrm{L}$ Tris-EDTA buffer $(\mathrm{pH}$ 9.0) for $3 \times 5$-minute cycles using a microwave oven and then incubated overnight with primary antibodies. The following antibody pairs were used in combination or alone as negative control: S100A4 (catalog number ab124805; rabbit)/p53 (catalog number M7001; mouse); S100A4 (catalog number 66489-1-Ig; mouse)/NMIIA (catalog number 11128-1-AP; rabbit); and NMIIA (catalog number 11128-1-AP; rabbit)/p53 (catalog number M7001; mouse). After washing, the slides were treated according to the 
Table 1 Association of S100A4, NMIIA, and p53 Expression with Clinicopathologic Factors in Ovarian High-Grade Serous Carcinoma

\begin{tabular}{|c|c|c|c|c|c|c|c|c|c|c|c|c|}
\hline \multirow[b]{3}{*}{ Factor } & \multicolumn{4}{|c|}{ S100A4 expression } & \multicolumn{4}{|c|}{ NMIIA expression } & \multicolumn{4}{|c|}{ p53 expression } \\
\hline & \multirow[b]{2}{*}{$n$} & \multirow{2}{*}{$\begin{array}{l}\text { High } \\
\text { (score } \geqq 6) \\
n(\%)\end{array}$} & \multirow{2}{*}{$\begin{array}{l}\text { Low } \\
\frac{(\text { score }<6)}{n(\%)}\end{array}$} & \multirow{2}{*}{$P$ value } & \multirow[b]{2}{*}{$n$} & \multirow{2}{*}{$\begin{array}{l}\text { High } \\
\text { (score } \geqq 3) \\
n(\%)\end{array}$} & \multirow{2}{*}{$\begin{array}{l}\text { Low } \\
\frac{(\text { score }<2)}{n(\%)}\end{array}$} & \multirow{2}{*}{$P$ value } & \multirow[b]{2}{*}{$n$} & \multirow{2}{*}{$\begin{array}{l}\text { High } \\
(\text { score } \geqq 8) \\
n(\%)\end{array}$} & \multirow{2}{*}{$\begin{array}{l}\text { Low } \\
\frac{(\text { score }<7)}{n(\%)}\end{array}$} & \multirow{2}{*}{$P$ value } \\
\hline & & & & & & & & & & & & \\
\hline \multicolumn{13}{|l|}{ Age } \\
\hline Young ( $<60$ years) & 39 & $23(58.9)$ & $16(41.1)$ & & 34 & $11(32.4)$ & $23(67.6)$ & & 35 & $28(80)$ & $7(20)$ & \\
\hline I & 10 & $2(20)$ & $8(80)$ & & 7 & $1(14.3)$ & $6(85.7)$ & & 6 & $3(50)$ & $3(50)$ & \\
\hline II-IV & 87 & $50(57.5)$ & $37(42.5)$ & 0.02 & 76 & $27(35.5)$ & $49(64.5)$ & 0.2 & 72 & $50(69.4)$ & $22(30.6)$ & 0.3 \\
\hline \multicolumn{13}{|l|}{ Tumor size, cm } \\
\hline$<8.4$ & 50 & $27(54)$ & $23(46)$ & & 39 & $11(28.2)$ & $28(71.8)$ & & 39 & $30(76.9)$ & $9(23.1)$ & \\
\hline$\geqq 8.4$ & 37 & $23(62.2)$ & $14(37.8)$ & 0.44 & 28 & $9(32.1)$ & $19(67.9)$ & 0.7 & 29 & $17(58.6)$ & $12(41.4)$ & 0.1 \\
\hline \multicolumn{13}{|l|}{ LN metastasis } \\
\hline Positive & 16 & $15(93.8)$ & $1(6.2)$ & & 12 & $3(25)$ & $9(75)$ & & 14 & $11(78.6)$ & $3(21.4)$ & \\
\hline Negative & 71 & $35(49.3)$ & $36(50.7)$ & 0.001 & 55 & $17(30.9)$ & $38(69.1)$ & 0.6 & 54 & $36(66.7)$ & $18(33.3)$ & 0.4 \\
\hline
\end{tabular}

LN, lymph node.

manufacturer's protocol using the Duolink Detection Kit with proximity ligation assay (PLA) PLUS and MINUS probes for mouse and rabbit (Olink Bioscience, Uppsala, Sweden). The PLA signal score was determined on the basis of the percentage of PLA signal-positive cells $(1,<10 \%$ positive cells; $2,10 \%$ to $30 \%$ positive cells; $3,30 \%$ to $50 \%$ positive cells; and $4,>50 \%$ positive cells) and the PLA signal intensity ( 0 , none; 1 , weak; 2 , moderate; and 3 , strong) with the multiplication of values of the two parameters.

\section{Methylation Analysis of S100A4}

Methylation status of the S100A4 gene was determined by methylation-specific PCR, as described previously. ${ }^{22}$ Briefly, genomic DNA extracted from cell lines using a Wizard Genomic DNA Purification kit (Promega, Madison, WI) and from clinical samples using a QIAamp DNA FFPE Tissue kit (Qiagen, Hilden, Germany) was treated with bisulfate using an EZ DNA Methylation-Gold kit (ZYMO Research, Orange, CA). Bisulfate-treated DNA was amplified by PCR using specific primers, as described previously. $^{22}$ The amplified signals were also analyzed by ImageJ software version 1.41 , and the S100A4 methylation score was calculated by the ratio of methylated relative to unmethylated signal intensities. The scores were divided into two categories (high and low) with mean values as the cutoff.

\section{Mutation Analysis for TP53}

Exons 5 to 9 of the TP53 gene were amplified by PCR, and the products were subjected to direct sequencing PCR, as described previously. ${ }^{23}$

\section{Statistical Analysis}

Comparative data were analyzed using the $U$-test. Overall survival (OS) was calculated as the time between onset and death or the date of the last follow-up evaluation. Progression-free survival (PFS) was also examined from the onset of treatment until relapse, disease progression, or last follow-up evaluation. OS and PFS were estimated using the Kaplan-Meier methods, and the statistical comparisons were made using the log-rank test. Univariate and multivariate analyses were performed using the Cox proportional hazards regression model. The cutoff for statistical significance was set as $P<0.05$.

\section{Results}

\section{Knockdown of S100A4 Results in Decreased Cell Proliferation and Increased Apoptosis}

Three HGSC cell lines (OVCAR-3, OVKATE, and OVSAHO) showed abundant endogenous S100A4 and NMIIA mRNA and protein expression and had TP53 abnormalities (Supplemental Figure S1A). Because aberrant DNA hypomethylation increases expression of $S 100 A 4,^{22}$ we examined methylation in the first intron of S100A4 in the three OHGSeCa cell lines and in two Em Ca cell lines (Supplemental Figure S1B). The methylation-specific PCR assay revealed that hypomethylation correlated with mRNA and protein expression levels in most cell lines; an exception was OVKATE cells, which displayed a combination of unmethylated and methylated introns, along with the abundant mRNA and protein expression (Supplemental Figure S1). 
p53 transcriptional ability in OVCAR-3 and Ishikawa cells harboring p53mt and p53wt, respectively, was also examined using Nutlin-3A, which inhibits the proteasomal degradation of p53 by antagonizing its interaction with murine double minute 2 (MDM2). ${ }^{24}$ The treatment resulted in a rapid increase in $\mathrm{p} 53$ protein levels, accompanied by an increase in expression of p53 transcriptional targets, including $p 21^{\text {wafl }}$ and bax in Ishikawa, but not OVCAR-3, cells. In addition, although $p 21^{\text {wafl }}$ promoter-driven luciferase was activated following transfection of $\mathrm{p} 53 \mathrm{wt}$, this was not the case with p53mt (Supplemental Figure S2A).

On the basis of the above findings, we established four OVCAR-3 clones in which S100A4 expression was blocked by an S100A4-specific shRNA (S100A4-KD). There were no alterations to expression of NMIIA and $\mathrm{p} 53$, nor to morphologic features in S100A4-KD cells when compared with control cells (Figure 1A). The S100A4-KD cells showed a tendency toward a low proliferative rate, particularly in the exponential growth phase, independent of cell cycle progression (Figure 1B).
To further evaluate altered expression of cell cycle-related molecules during growth, S100A4-KD cells were rendered quiescent by serum starvation and were subsequently stimulated with serum. At 9 and 24 hours after release into the cell cycle, there were no differences in expression levels of these markers between the S100A4-KD and control cells (Figure 1C). Treatment of the S100A4-KD cells with CDDP increased apoptosis when compared with that of control cells (Figure 1D), along with increased cleaved caspase-3, whereas X-linked inhibitor of apoptosis protein, $\mathrm{p} 53$, and bax expression remained unchanged (Figure 1E). In addition, the Cell Counting Kit-8 assay revealed that the viability of S100A4-KD cells in response to CDDP treatment at 24 hours was significantly reduced compared with that of the control cells (Figure 1F).

These findings suggest that $\mathrm{S} 100 \mathrm{~A} 4$ expression is associated with modulation of cell proliferation and susceptibility to apoptosis in HGSC cells.
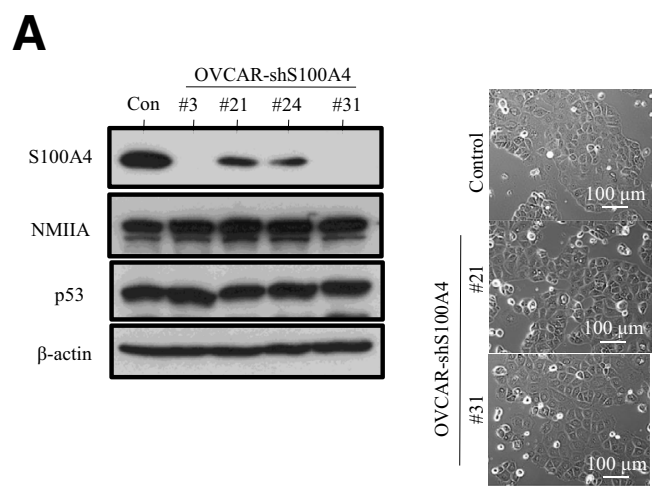

B
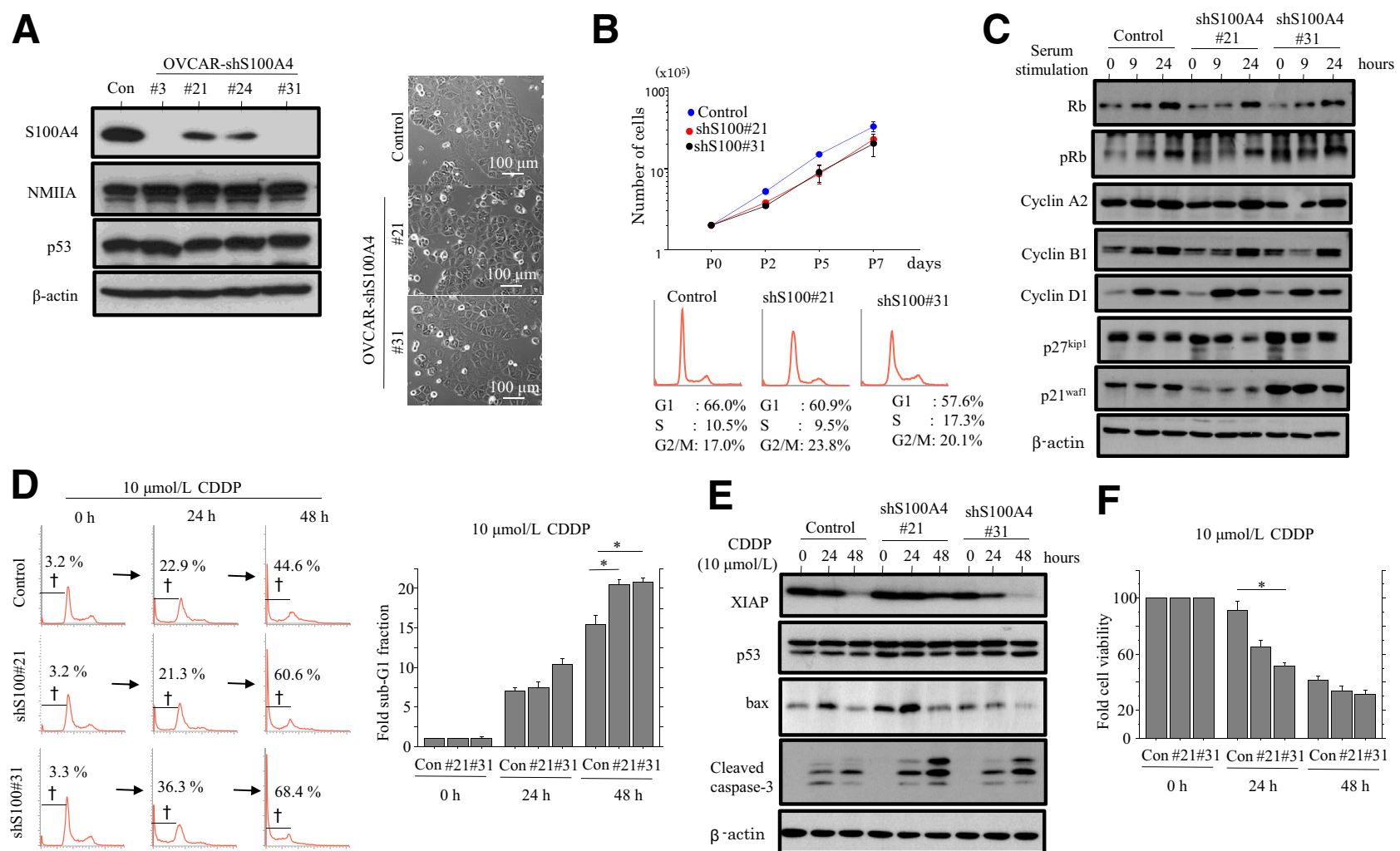

$\mathbf{E}$

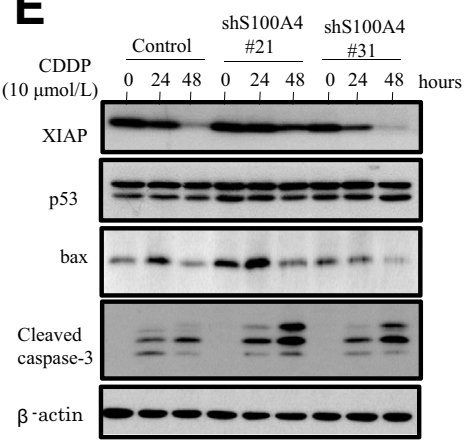

$\mathbf{F}$

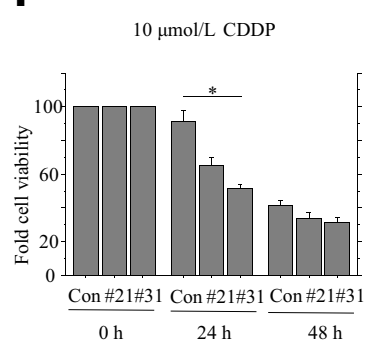

Figure 1 Changes in cell proliferation and apoptosis following knockdown of S100A4 in OVCAR-3 cells. A: Left panel: Western blot analysis for the indicated proteins of total lysates from controls (Con) and four different shRNAs. Right panel: Phase contrast images of S100A4-KD cells. B: Top panel: Two independent S100A4-knockdown (S100A4-KD) cell lines and control cells were seeded at low density. The cell numbers are presented. P0, P2, P5, and P7 are 0, 2, 5, and 7 days after cell passage, respectively. The experiment was performed in duplicate. Bottom panel: Flow cytometric cell cycle analysis of S100A4-KD and control cells at 5 days after cell passage (P5). C: Western blot analysis of the indicated proteins in S100A4-KD and control cells after serum stimulation for the times shown. D: S100A4-KD and control cells were treated with $10 \mu \mathrm{mol} / \mathrm{L}$ cisplatin (CDDP) for the times shown, and the percentage of cells undergoing apoptosis (sub- $\mathrm{G}_{1}$ ) was calculated following flow cytometry. Daggers indicate sub- $\mathrm{G}_{1}$ fractions. The experiment was performed in duplicate. E: Western blot analysis of the indicated proteins in S100A4-KD and control cells after $10 \mu \mathrm{mol} / \mathrm{L}$ CDDP treatment for the times shown. F: Treatment of S100A4-KD and Con with $10 \mu \mathrm{mol} / \mathrm{L}$ CDDP for the times shown. Cell viability was measured using the Cell Counting Kit-8. Cell viability in the absence of CDDP treatment (0 hours) is set as $100 \%$. The experiment was performed in duplicate. Data are expressed as means \pm SD (B, top panel, $\mathbf{D}$, right panel, and $\mathbf{F})$. ${ }^{*} P<0.05$. Scale bars $=$ $100 \mu \mathrm{m}(\mathbf{A})$. pRb phosphorylated Rb. 
Knockdown of S100A4 Decreases Cancer Stem Cell Features and Increases Cell Mobility

Epithelial-mesenchymal transition (EMT) promotes stem cell properties and confers cells with cancer stem cell (CSC)-like features. ${ }^{25}$ Because S100A4 is a normal stemness marker, ${ }^{6,26}$ we examined whether it was associated with EMT/CSC properties in HGSC cells. The S100A4-KD cells showed decreased expression of several EMT/CSC markers, including $\mathrm{N}$-cadherin, Twist1, Slug, vimentin, Sox2, and ALDH1, compared with those of control cells, in contrast to an increase in Snail expression (Figure 2A). This was consistent with the inability of p53mt, but not p53wt, to repress the Snail promoter (Supplemental Figure S2B). An Aldefluor assay also revealed a decrease in the ALDH $1^{\text {high }}$ activity population in the S100A4-KD cells, in line with the decreased number of well-defined, round spheroids that were $>50 \mathrm{~mm}$ in size (Figure 2B). To further examine correlations between S100A4-KD, EMT/CSC features, and cell mobility, we performed scratch and migration assays. The migration rate was significantly increased in S100A4$\mathrm{KD}$ cells (Figure 2C), in line with the accelerated refilling of wounded empty spaces (fold-change values, 0.3 to 0.4 ) when compared with the control cells (fold value, 0.7) (Figure 2D). These findings suggest that in HGSC cells, S100A4 induces CSC properties and inhibits cell motility, along with changes in expression of several EMT/CSCrelated markers.

\section{Inhibition of NMII Reduces Proliferation, Induces EMT/CSC Properties, and Increases the Mobility of HGSC Cells}

Because the biological activity of S100A4 is based on interactions with potential binding partners, ${ }^{12,13}$ we evaluated the function of NMII, a major partner for S100A4 $4{ }^{17}$ in HGSC cells. To this end, we used blebbistatin, a synthetic chemical compound that effectively and reversibly blocks the ATPase activity of NMII without inhibiting class I, V, and $\mathrm{X}$ myosin superfamily members, on the basis of the findings of previous studies. ${ }^{17,27,28}$ Treatment with the compound dramatically altered the morphology of OVCAR3 cells, which switched toward a fibroblastic appearance (Figure 3A), concomitant with increased expression of several EMT markers, including N-cadherin, ZEB1, Twist1, Slug, Snail, vimentin, and phosphorylated Smad2 at serine255 (Figure 3B). The treatment also significantly reduced growth rate and increased cell viability, whereas susceptibility to apoptosis was unaffected (Figure 3C). The Aldefluor assay revealed an increase in the ALDH $1^{\text {high }}$ activity population in blebbistatin-treated cells compared with the controls (Figure 4A), along with increased expression of S100A4 and several CSC markers, including CD133, Sox2, and ALDH1 (Figure 4B). In addition, scratch and migration assays revealed that blebbistatin significantly enhanced cellular migration capability (Figure 4, C and D). These findings suggest that inhibition of NMII elicits the opposite effects on CSC properties and cell viability when compared with S100A4-KD cells, whereas it phenocopies the knockdown results with regard to cell proliferation and migration.

\section{Epigenetic, Genetic, and IHC Findings in Clinical HGSC Cases}

Representative IHC findings for S100A4, NMIIA, and p53, as well as several EMT/CSC-related markers in HGSC and low-grade serous carcinoma, are illustrated in Figure 5A. Nuclear/cytoplasmic immunostaining for S100A4 and ALDH1, cytoplasmic immunoreactivity for NMIIA, Nestin, and vimentin, and nuclear or membrane staining for $\mathrm{p} 53$, Sox2, Ki-67, CD133, and E-cadherin were observed in tumor cells of both subtypes. Average IHC scores for S100A4, NMIIA, and vimentin were significantly higher in low-grade serous carcinoma than in HGSC, whereas p53 scores and Ki-67 labeling indexes were significantly higher in the latter (Figure 5B). With a few exceptions, there were no significant correlations between any of the IHC markers investigated (Supplemental Table S1).

Methylation of the S100A4 gene was observed in 51 (50.5\%) of 101 HGSCs, but there was no association between S100A4 methylation score and the IHC scores (Supplemental Figure S3A). Although TP53 mutations were found in $90(77.5 \%)$ of 116 HGSCs, TP53 status was not associated with any of IHC markers investigated, with the exception of p53 and Ki-67 immunohistochemistry (Supplemental Figure S3B).

Interactions between S100A4, NMIIA, and p53 in HGSC

To examine the interactions between S100A4, NMIIA, and p53, we performed an in situ PLA assay using antibodies targeting S100A4, NMIIA, and p53 in 10 HGSC cases harboring p53mt (Figure 5C). Interactions of p53 with either S100A4 or NMIIA were observed in the nuclei, whereas the S100A4/NMIIA interaction was in both nuclear and cytoplasmic compartments. The PLA score for the S100A4/ NMIIA interaction was significantly lower than the score for either S100A4/p53mt or NMIIA/p53mt. These associations were also confirmed by co-IP of p53 (but not anti-S100A4 or anti-NMIIA) in OVCAR-3 cells (Supplemental Figure S4).

\section{S100A4, but Not NMIIA or p53, Is Associated with Unfavorable Prognosis in HGSC}

The S100A4 score was significantly higher in advanced clinical stages and distant tumor metastasis, whereas such associations were not observed for the NMIIA and p53 scores (Table 1). Kaplan-Meier curves showed that HGSC patients with high S100A4 scores had poorer OS and PFS when compared with patients with low scores, but such associations were not observed with regard to NMIIA and p53 scores (Figure 6). Univariate Cox progression hazards regression 


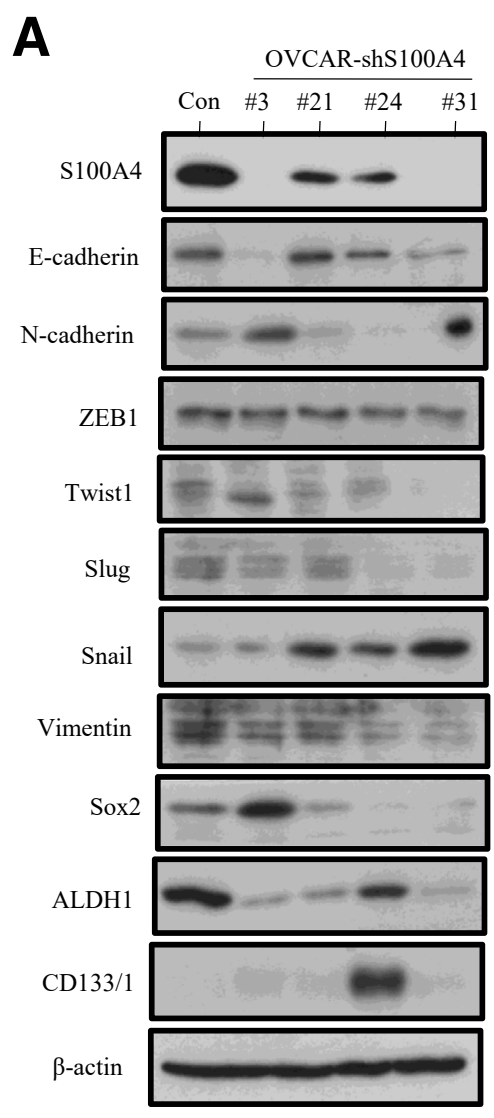

C

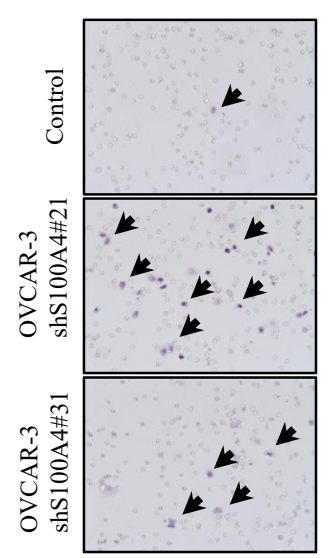

B
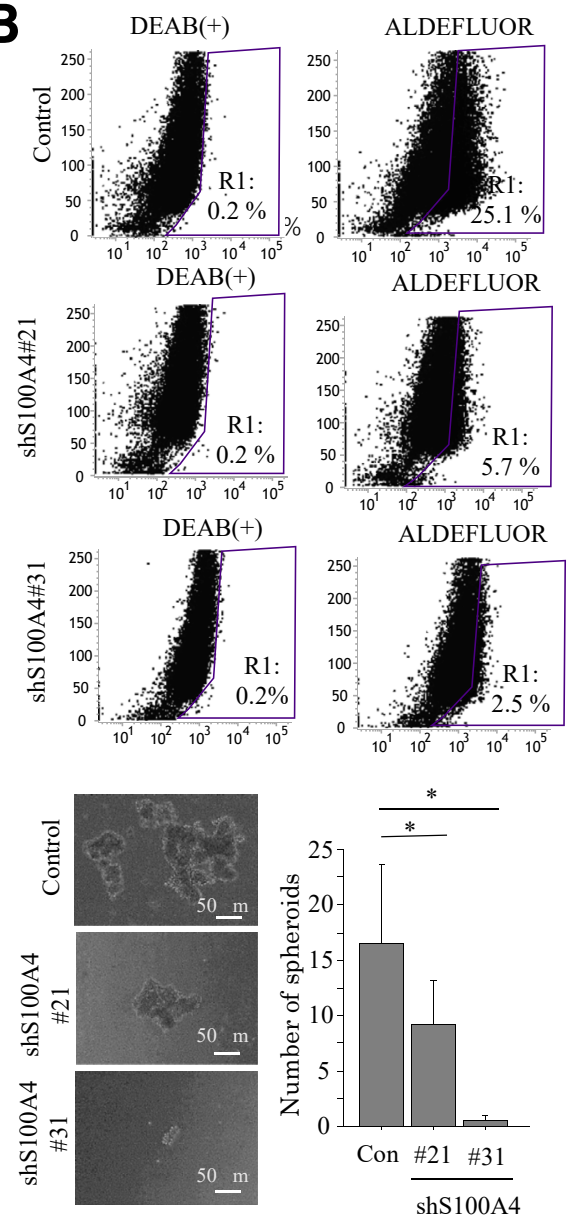

Figure 2 Changes in cancer stem cell properties and cell migration in S100A4-knockdown (S100A4KD) cells. A: Western blot analysis for the indicated proteins of total lysates from controls (Con) and four different shRNAs. B: Top panel: Aldefluor analysis of S100A4-KD and control cells. Cells negative for aldehyde dehydrogenase 1 (ALDH1) activity are located in the area to the far left of each plot, and the positive cells are in black gate (R1). The percentage of live single-cell population contained in each gate is shown. Bottom left panel: Phase-contrast photograms of spheroids by S100A4-KD and control following 2 weeks of growth. Bottom right panel: The numbers of spheroids are presented. C: Migration rate measured using a transwell assay. Left panel: S100A4-KD cells and the control cells were seeded in a 24-well transwell plate and incubated for 24 hours in medium without serum. Migrated cells (arrowheads) were stained by hematoxylin-eosin and counted using a light microscope. Right panel: The cell numbers are presented. The experiment was performed in duplicate. D: Wound healing assay with S100A4-KD and control cells. Left panel: $A$ scratch was made in the middle of a layer of confluent cells, and phase contrast images were taken 6 and 20 hours later. The red lines indicate borderlines between confluent cell layers and wound areas. Right panel: The values of wound areas were calculated using ImageJ software version 1.41 with those at 0 hours set as 1 . The fold wound areas are presented. The experiment was performed in duplicate. Data are expressed as means \pm SD. ${ }^{*} P<0.05$. Scale bars $=50 \mu \mathrm{m}(\mathbf{B})$; $500 \mu \mathrm{m}$ (D). DEAB, N,N-diethylaminobenzaldehyde.
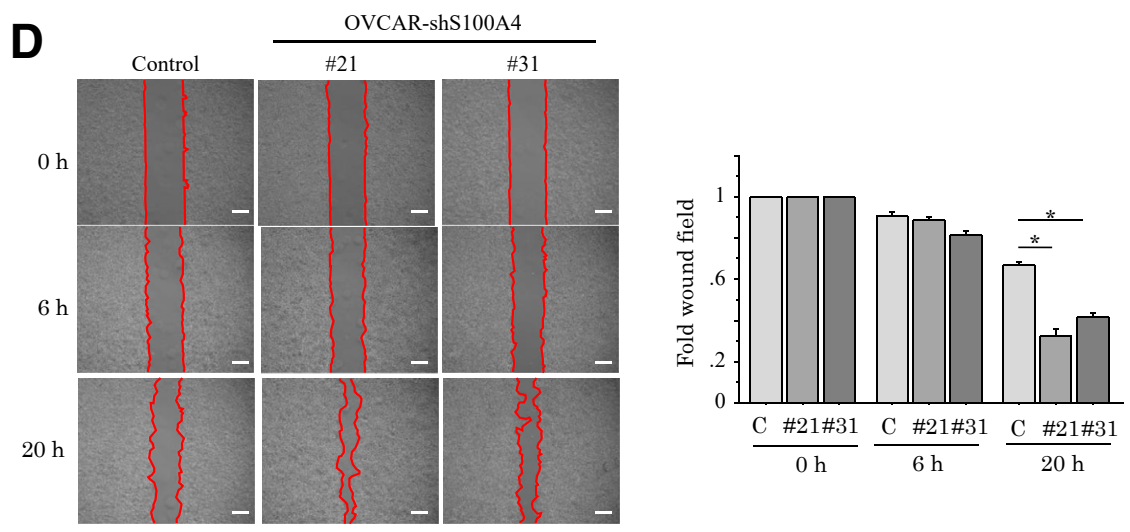
A
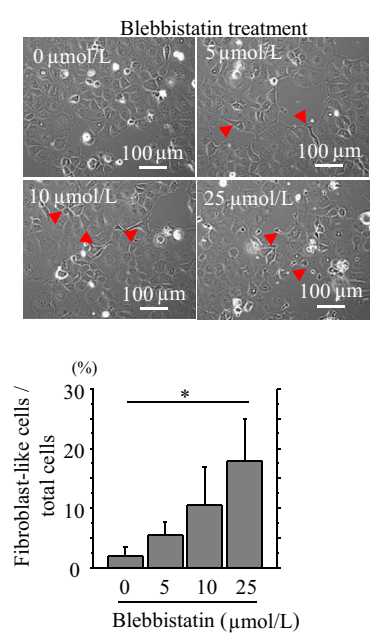

B

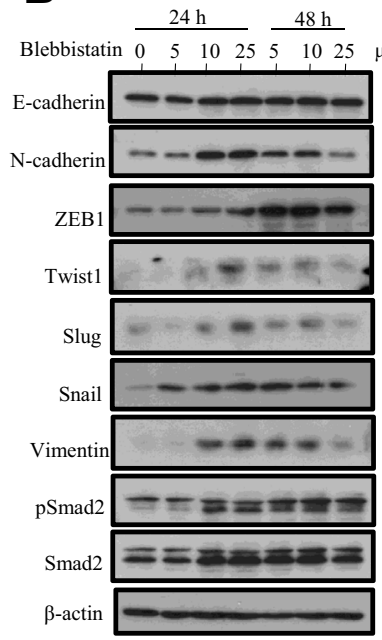

C
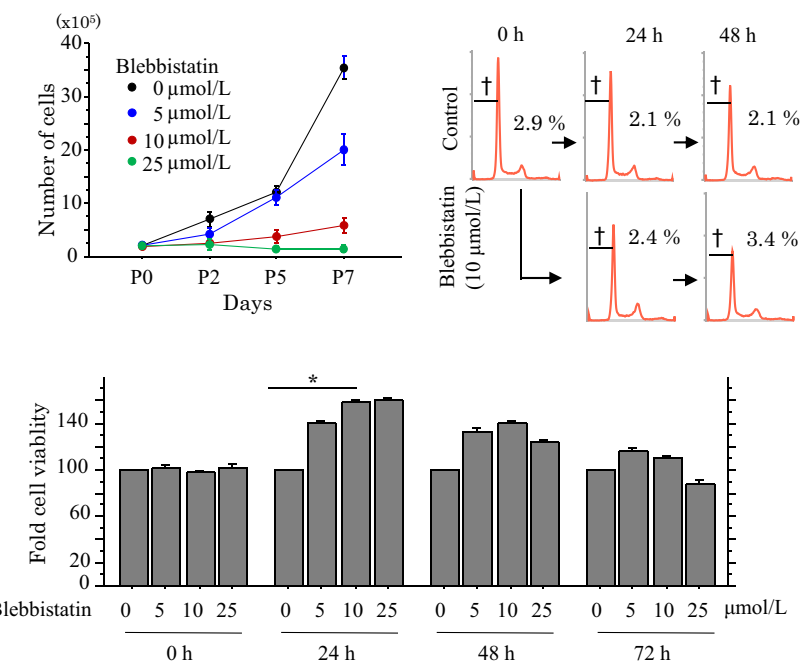

Figure 3 Inhibition of NMIIA by blebbistatin alters cell morphology, proliferation, and viability in OVCAR-3 cells. A: Top panel: Phase-contrast image of OVCAR-3 cells following treatment with blebbistatin treatment at the indicated dosage for 72 hours. Note the switch toward a fibroblast-like morphology (arrowheads). Bottom panel: Percentages of fibroblast-like cells relative to total cells per high-power field. B: Western blot analysis of the indicated proteins in OVCAR-3 cell lysates after $10 \mu \mathrm{mol} / \mathrm{L}$ blebbistatin treatment for the times shown. C: Top left panel: OVCAR-3 cells were seeded at low density with the indicated dosage of blebbistatin. Cell numbers are presented. P0, P2, P5, and P7 are 0, 2, 5, and 7 days after cell passage, respectively. Top right panel: After treatment of S100A4-knockdown and control cells with $10 \mu \mathrm{mol} / \mathrm{L}$ blebbistatin for the times shown, cells undergoing apoptosis (sub- $\mathrm{G}_{1}$ ) were detected by flow cytometry. Daggers indicate sub- $\mathrm{G}_{1}$ fractions. Bottom panel: OVCAR-3 cells were treated with blebbistatin at the indicated dosage for the times shown. Cell viability was measured using the Cell Counting Kit-8. Cell viability in the absence of blebbistatin treatment is set as $100 \%$ at each time point. The experiment was performed in duplicate. Data are expressed as means \pm SD (A, bottom panel, and $\mathbf{C}$, top left and bottom panels). ${ }^{\star} P<0.05$. Scale bars $=100 \mu \mathrm{m}(\mathbf{A})$. pSmad2, phosphorylated Smad2.

revealed that $\mathrm{S} 100 \mathrm{~A} 4$, lymph node metastasis, and distant metastasis were significant prognostic factors for OS or PFS in HGSC. Multivariate Cox regression analysis also showed that S100A4 and lymph node metastasis were significant and independent prognostic factors for PFS, but not OS (Table 2). Collectively, these findings suggest that S100A4, but neither NMIIA nor p53, is a useful factor for prognostic prediction of HGSC.
A

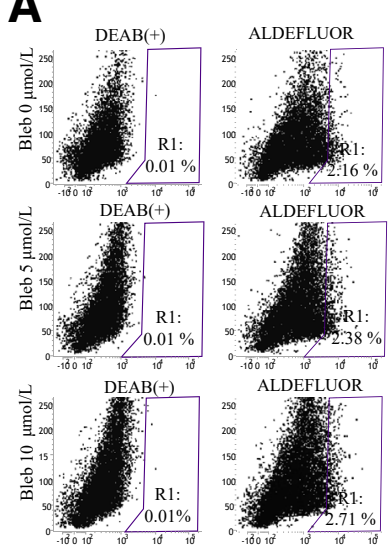

B

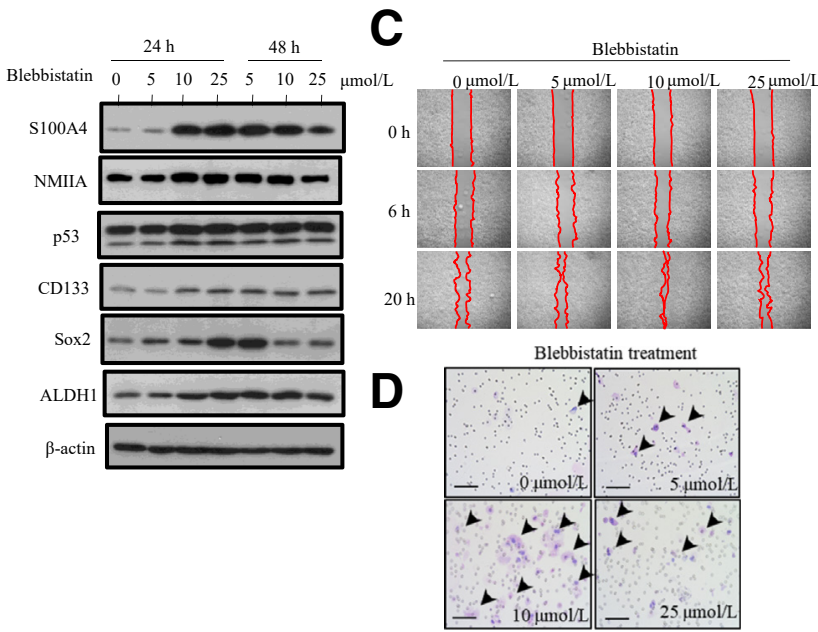

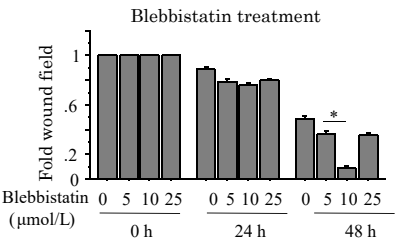

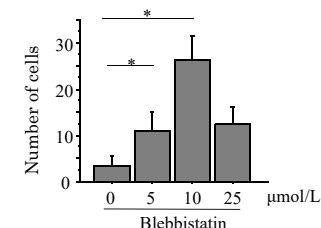

Figure 4 Inhibition of NMIIA by blebbistatin alters cancer stem cell properties and migration in OVCAR-3 cells. A: Aldefluor analysis in 0VCAR-3 cells after blebbistatin treatment with the indicated dosage for 24 hours. Cells negative for aldehyde dehydrogenase 1 (ALDH1) activity are located in the area to the far left of each plot, and the positive cells are in black gate (R1). The percentage of live single cell population contained in each gate is shown. B: Western blot analysis of the indicated proteins in OVCAR-3 cell lysates after blebbistatin treatment. C: Wound healing assay with 0VCAR-3 cells after blebbistatin treatment with the indicated dosage. Top panel: A scratch was made in the middle of a layer of confluent cells, and phase-contrast images were taken 6 and 20 hours later. The red lines indicate borderlines between confluent cell layers and wound areas. Bottom panel: The values of wound areas were calculated using ImageJ software version 1.41, and those in 0 hours were set as 1 . The fold wound areas are presented. The experiment was performed in duplicate. D: Migration rate measured using a transwell assay. Top panel: OVCAR-3 cells were seeded in a 24-well transwell plate and incubated in medium without serum after blebbistatin treatment with the indicated dosage for 24 hours. Migrated cells (arrowheads) were stained by hematoxylin-eosin and counted using a light microscope. Bottom panel: The cell numbers are presented. The experiment was performed in duplicate. Data are expressed as means \pm SD. ${ }^{*} P<0.05$. Scale bars $=100 \mu \mathrm{m}($ D) . DEAB, dietthykaminobenzaldehyde. 
A

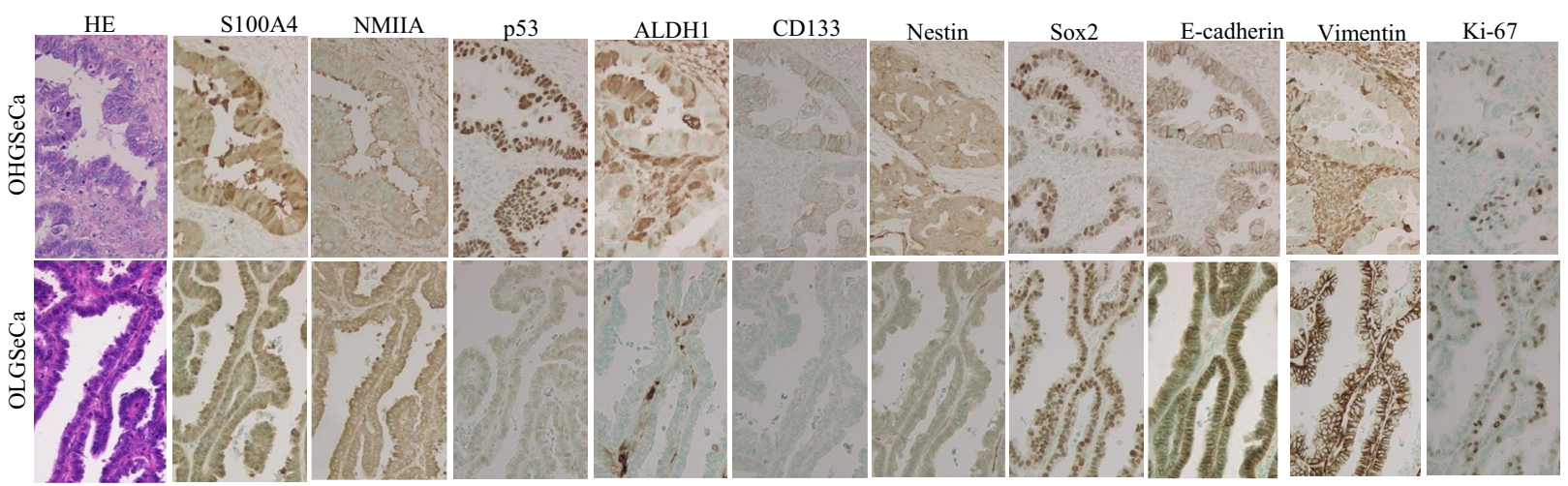

B
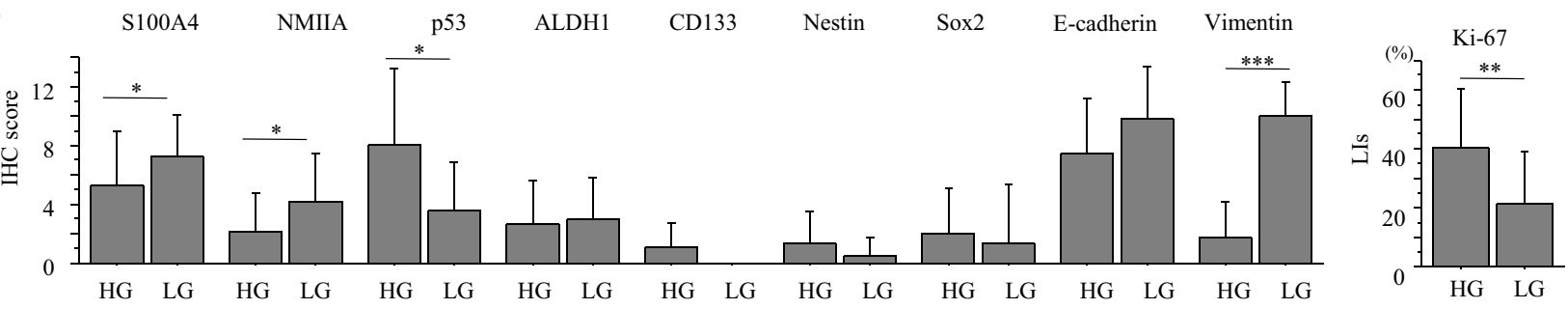

C
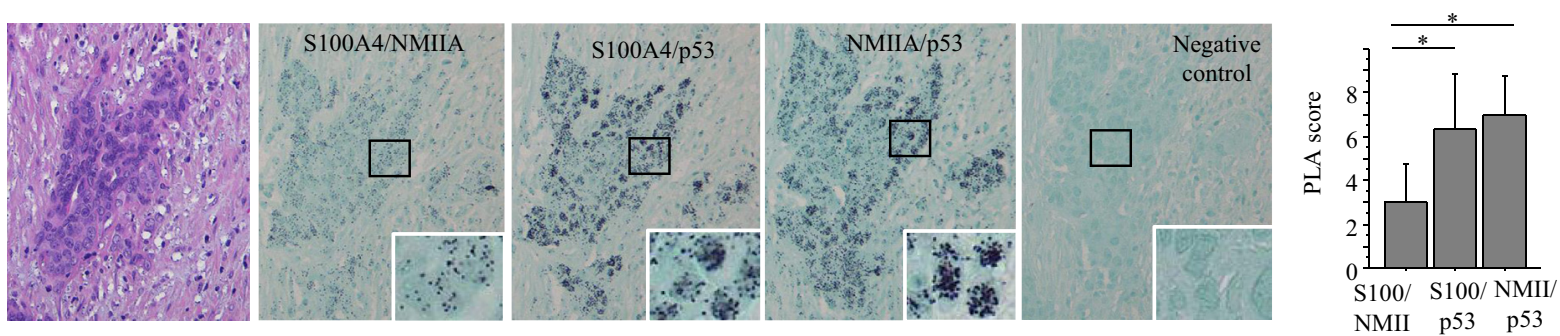

Figure 5 Immunohistochemistry (IHC) findings in serial sections of high-grade serous carcinoma (HGSC) and/or low-grade serous carcinoma (LGSC). A: Staining by hematoxylin-eosin (HE) and IHC for the indicated proteins in HGSC (top row) and LGSC (bottom row). B: IHC score and labeling indexes (LIs) for the indicated molecules in HGSC and LGSC. C: Left panels: In situ proximity ligation assay (PLA) of S100A4/NMIIA, S100A4/p53, and NMIIA/p53 interactions in HGSC cases. Note the small aggregated dots in cytoplasmic and/or nuclear compartments of the tumor cells. Right panel: PLA score for the indicated combinations of S100A4, NMIIA, and p53 in HGSC. Data are expressed as means \pm SD. ${ }^{*} P<0.05, * * P<0.01$, and ${ }^{* * * P}<0.001$. Original magnification, $\times 100(A) ; \times 200$ (C, main images); $\times 400$ (C, insets). ALDH1, aldehyde dehydrogenase 1; HG, high grade; LG, low grade.

\section{Analysis of TCGA HGSC Data}

We further examined the associations between expression of S100A4 and MYH9 (NMIIA) mRNA, as well as TP53 gene status, in HGSC using TCGA data. There were no differences in $M Y H 9$ (NMIIA) mRNA expression between high and low S100A4 mRNA categories (Supplemental Figure S5A). No differences in the expression levels of S100A4 and MYH9 (NMIIA) mRNAs were observed between p53wt and p53mt categories (Supplemental Figure S5B). Finally, Kaplan-Meier curves showed neither expression of S100A4 and MYH9 (NMIIA) nor TP53 gene status was prognostic factor for OS and PFS (Supplemental Figure S5C).

\section{Discussion}

The present study clearly provides evidence that methylation status within the first intron of the S100A4 gene is closely associated with mRNA and protein expression in most HGSC and Em Ca cell lines; these findings are consistent with those of other studies for endometrial and pancreatic carcinomas. ${ }^{2,29}$ However, methylation scores were not associated with the IHC scores in HGSC tissues. Given our previous data showing NF- $\kappa \mathrm{B} / \mathrm{p} 65-$ dependent transactivation of the S100A4 promoter and increased mRNA expression in Em Ca cells ${ }^{17}$ it is possible that microenvironmental factors (including those that trigger $\mathrm{NF}-\kappa \mathrm{B}$ signaling) may also contribute to the regulation of S100A4 expression within HGSC tissues.

Although TCGA Research Network demonstrates that HGSC is characterized by TP53 mutations in up to $96 \%$ of the cases, ${ }^{30}$ we found mutations in $77.5 \%$ of HGSC cases, in line with other reports showing the frequency in $60 \%$ to $70 \%$ of the cases. ${ }^{31,32}$ The discrepant results may be due to differences in samples used (fresh versus paraffin embedded), the exons targeted for sequencing (exons 2 to 11 versus exons 5 to 8 or 9), and the detection assay used (RNA versus DNA sequencing). 

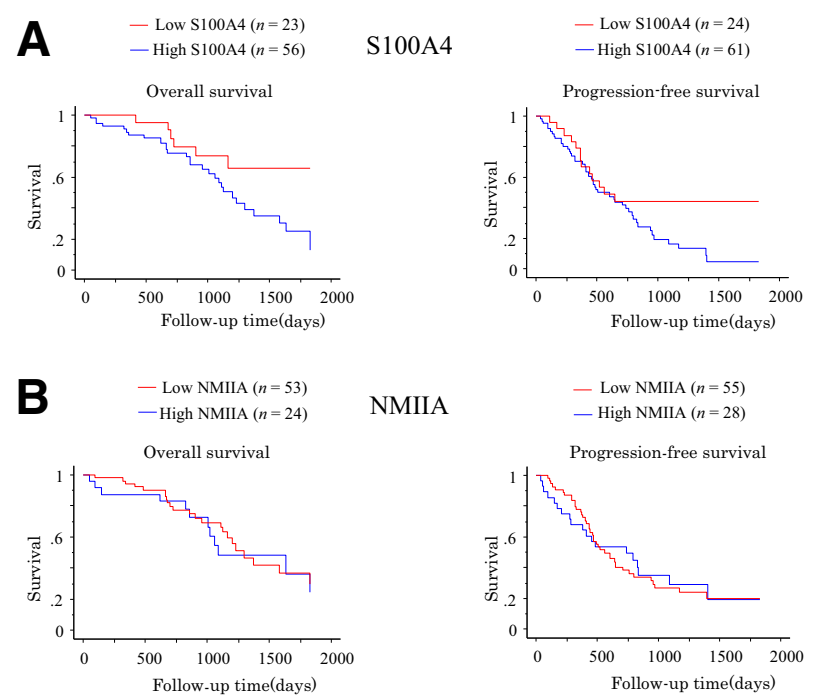

\section{NMIIA}

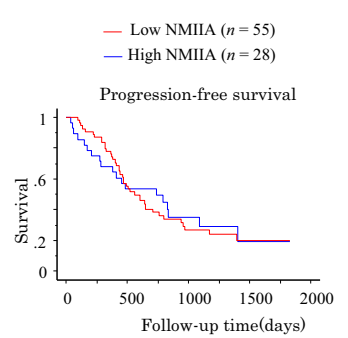

C $\quad \begin{aligned} & - \text { Low } p 53(n=31) \\ & -\operatorname{High} p 53(n=47)\end{aligned}$
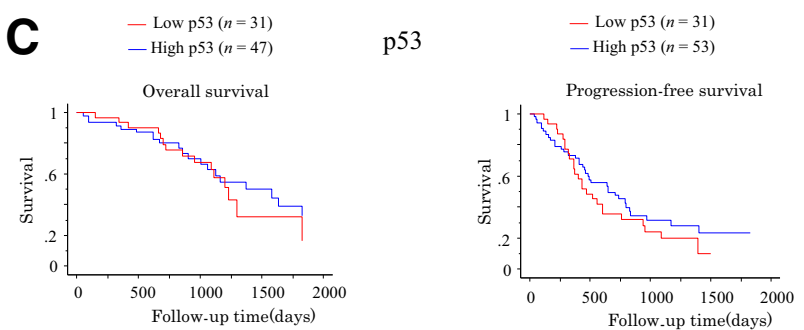

Figure 6 Relationship of S100A4, NMIIA, and p53 expression with prognosis in high-grade serous carcinoma (HGSC). Overall survival (OS; left panels) and progression-free survival (PFS; right panels) in S100A4 (A), NMIIA (B), and p53 expression (C) in the HGSC. Log-rank test: $P<0.03$ (OS), $P<0.04$ (PFS; A); $P=0.7$ (OS), $P=0.8$ (PFS; B); $P=0.6$ (OS), $P=0.3$ (PFS; C).
In this study, the interactions between S100A4, NMIIA, and p53 were observed in complex samples containing coIP products from OVCAR-3 cells when anti-p53, but not anti-NMIIA or anti-S100A4, antibodies were used. Although several in vitro binding assays have shown a direct interaction between recombinant p53 and $\mathrm{S} 100 \mathrm{~A} 4,{ }^{33,34}$ these data have not been replicated in cells previously. ${ }^{35}$ This indicates that the complex is short lived or dependent on a high local concentration of the interactors or intactness of subcellular compartments. ${ }^{36}$ One possible reason for the anomalous results may also include a difference in detection sensitivity among the three antibodies used in this study.

The in situ PLA assay also confirmed the findings from the co-IP experiments, demonstrating that these interactions were located within cytoplasmic and/or nuclear compartments of tumor cells harboring p53mt. Significant differences between the S100A4/NMIIA PLA scores and either the S100A4/p53mt or NMIIA/p53mt scores may be due to higher levels of p53 expression compared with S100A4 or NMIIA expression. We infer this based on the finding that TP53 mutations were significantly associated with high p53 IHC score, as well as high Ki-67 labeling index values. Our conclusion is also supported by evidence that S100A4 has a 300- to 500-fold higher affinity for $\mathrm{p} 53 \mathrm{wt}$ and some $\mathrm{p} 53 \mathrm{mt}$ variants when compared with NMIIA. ${ }^{37}$

More important, S100A4 knockdown was closely associated with decreased CSC properties, along with decreases in expression of some stemness markers, the ALDH $1^{\text {high }}$ population, and spheroid formation. In contrast, opposite

Table 2 Univariate and Multivariate Analysis for Overall Survival and Progression-Free Survival in Ovarian High-Grade Serous Carcinoma

\begin{tabular}{|c|c|c|c|c|c|c|c|c|c|}
\hline \multicolumn{4}{|l|}{ Univariate analysis } & \multirow[b]{2}{*}{$\begin{array}{l}\text { Unfavorable } \\
\text { factor }\end{array}$} & \multicolumn{5}{|l|}{ Multivariate analysis } \\
\hline Variables & Cutoff & Log-rank c2 & $P$ value & & Variable & Cutoff & $\begin{array}{l}\text { Hazard } \\
\text { ratio }\end{array}$ & $95 \%$ CI & $P$ value \\
\hline S100A4 & $3 / 4$ & 5.01 & 0.02 & High score & S100A4 & $3 / 4$ & 3.59 & $0.75-17.08$ & 0.1 \\
\hline NMIIA & $2 / 3$ & 0.11 & 0.7 & & LN metastasis & $-/+$ & 0.37 & $0.14-1.0$ & 0.05 \\
\hline p53 & $7 / 8$ & 0.29 & 0.6 & & & & & & \\
\hline LN metastasis & $-/+$ & 8.35 & 0.003 & & & & & & \\
\hline Distant metastasis & $-/+$ & 0.69 & 0.4 & & & & & & \\
\hline Residual tumor after surgery & Present/absent & 1.42 & 0.2 & & & & & & \\
\hline Progression-free survival & & & & & $\begin{array}{l}\text { Progression-free } \\
\text { survival }\end{array}$ & & & & \\
\hline Tumor size, cm & $8.4 / 8.5$ & 0.82 & 0.3 & Large size & & & & & \\
\hline LN metastasis & $-/+$ & 9.65 & 0.001 & LN metastasis & & & & & \\
\hline Distant metastasis & $-/+$ & 5.93 & 0.01 & & & & & & \\
\hline Residual tumor after surgery & Present/absent & 0.87 & 0.4 & & & & & & \\
\hline
\end{tabular}

LN, lymph node. 
effects, along with the increased S100A4 expression, were elicited by the specific inhibition of NMIIA activity. Because S100A4 can inhibit the actin-dependent ATPase activity of NMIIA, ${ }^{38,39}$ we suggest that S100A4-mediated inhibition of NMIIA may serve as a critical regulator of CSC properties in HGSC cells. In fact, S100A4 directly contributes to the self-renewal and survival of glioblastoma and head and neck tumors, ${ }^{40,41}$ whereas NMII activity directs the differentiation of stem cells to specific tissue lineages. ${ }^{14}$

We also identified an anti-apoptotic role of S100A4 in HGSC cells, because S100A4 knockdown increased susceptibility to apoptosis in response to CDDP treatment, whereas the inhibition of NMIIA activity enhanced cell viability but not apoptosis. S100A4 potentially affects the balance of p53 modifications in its negative regulatory domain, resulting in increased p53-MDM2 affinity and increased p53 ubiquitination and degradation. ${ }^{24}$ However, OVCAR-3 cells harboring p53mt had high p53 and bax expression levels, independent of the inhibition of p53MDM2 interaction by Nutlin-3A treatment. In addition, expression of both p53 and bax was unaffected by treatment of S100A4-KD cells with CDDP, indicating that increased apoptosis in S100A4-KD cells may be p53 independent. A similar finding was also reported in pancreatic carcinoma. ${ }^{42}$ Interestingly, p53mt and p53wt activate apoptotic signaling through distinct molecular mechanisms. ${ }^{43}$

In our results, treatment of OVCAR-3 cells with blebbistatin reduced the proliferative rate and enhanced migration capability; it also increased the expression of several EMT/CSC-related molecules, in line with the results of our previous study using Em Ca cells. ${ }^{17}$ Because S100A4 selectively promotes the monomeric and unassembled state of the NMIIA, ${ }^{44}$ we expected that S100A4 knockdown would induce phenotypes that were opposite to those induced by inhibition of NMIIA. However, S100A4

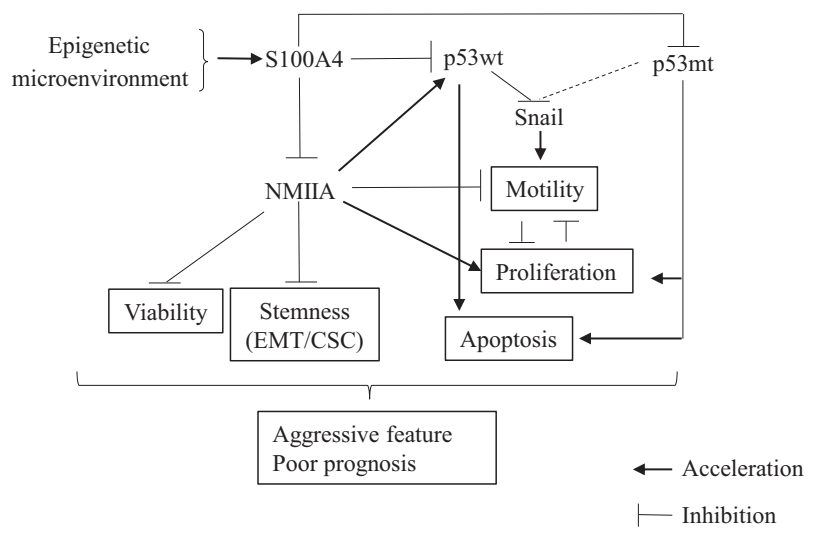

Figure 7 Schematic representation of the role of the S100A4/NMIIA/ p53 axis in high-grade serous carcinoma. Aggressive and poor prognostic features are elicited through modulation of epithelial-mesenchymal transition (EMT)/cancer stem cell (CSC) features and tumor cell viability, as well as cell mobility, proliferation, and apoptosis. p53mt, mutant p53; p53wt, wild-type p53. knockdown phenocopied the results of blebbistatin with regard to proliferation and mobility. Furthermore, S100A4 knockdown increased Snail expression without the induction of EMT features. Given that only p53wt, but not p53mt, can repress Snail promoter activity, it is possible that loss of p53 function may increase cell mobility because of derepression of Snail expression, because Snail can increase the movement of cells even when they have not undergone a full EMT. ${ }^{45}$ In addition, the enhanced cell migration capability may explain the low proliferation status in both cell conditions, because previous studies have reported an inverse correlation between cell proliferation and mobility. ${ }^{46-48}$

Finally, S100A4 score was significantly associated with some unfavorable clinicopathologic factors in HGSC cases. Patients with high expression of S100A4 protein, but not NMIIA and p53, had significantly worse OS and PFS than did patients with low expression of S100A4. S100A4 protein level is a better predictor of OS and PFS in HGSC than is S100A4 mRNA, because there was no correlation between the latter and clinical outcomes. Moreover, multivariate Cox regression analysis showed that S100A4 and lymph nodal metastatic factor were significant and independent unfavorable prognostic factors for PFS. These findings suggest that S100A4, but not NMIIA and p53, may be a key factor for HGSC prediction and prognosis. Our observations that S100A4, NMIIA, and vimentin were significantly higher in low-grade serous carcinoma than in HGCS may be because of differences in the immunophenotypic characteristics between these two histotypes, as well as the mutation status of the KRAS, BRAF, ERBB2, or TP53 genes. ${ }^{49}$

Together, our results suggest a novel functional role of S100A4/NMIIA/p53-related signaling in HGSC (Figure 7). Overexpression of S100A4 and its interaction with NMIIA, as well as p53wt and p53mt, induces EMT and CSC phenotypes and alters cell proliferation, apoptosis, and migration capability, each of which contributes to an unfavorable outcome in HGSC. Loss of p53 function may also contribute to the establishment and maintenance of S100A4/ NMIIA-related phenotypic characteristics in HGSC.

\section{Author Contributions}

A.H., Y.O., A.Y., and M.S. performed most of the experiments, analyzed the data, and wrote the manuscript; T.M., Y.O., M.T., M.H., J.Z., M.T., and M.N assisted in performing the experiments, analyzing the data, and writing the manuscript; all authors reviewed and approved the final manuscript.

\section{Supplemental Data}

Supplemental material for this article can be found at http://doi.org/10.1016/j.ajpath.2020.07.014. 


\section{References}

1. Lee J-Y, Kim E-Y, Jung K-W, Shin A, Chan KKL, Aoki D, Kim JW, Low JJH, Won Y-J: Trends in gynecologic cancer mortality in East Asian regions. J Gynecol Oncol 2014, 25:174-182

2. Yamagami W, Nagase S, Takahashi F, Ino K, Hachisuga T, Aoki D, Katabuchi H: Clinical statistics of gynecologic cancer in Japan. J Gynecol Oncol 2017, 28:e32

3. Schummer M, Ng WV, Bumgarner RE, Nelson PS, Schummer B, Bednarski DW, Hassell L, Baldwin RL, Karlan BY, Hood L: Comparative hybridization of an array of 21,500 ovarian DNAs for the discovery of genes overexpressed in ovarian carcinomas. Gene 1999, 238:375-385

4. Yan W, Chen J, Chen Z, Chen H: Deregulated miR-296/S100A4 axis promotes tumor invasion by inducing epithelial-mesenchymal transition in human ovarian cancer. Am J Cancer Res 2016, 6:260-269

5. Eisenhauer EL, Abu-Rustum NR, Sonoda Y, Aghajanian C, Barakat RR, Chi DS: The effect of maximal surgical cytoreduction on sensitivity to platinum-taxane chemotherapy and subsequent survival in patients with advanced ovarian cancer. Gynecol Oncol 2008, 108: 276-281

6. Mazzuccchelli L: Protein S100A4: too long overlooked by pathologist? Am J Pathol 2002, 160:7-13

7. Donato R: Intracellular and extracellular roles of S100 proteins. Microsc Res Tech 2003, 60:540-551

8. Malashkevch VN, Varney KM, Garrett SC, Wilder PT, Knight D, Charpentier TH, Ramagopal UA, Almo SC, Weber DJ, Bresnick AR: Structure of $\mathrm{Ca}^{2+}$-bound S100A4 and its interaction with peptides derived from nonmuscle myosin-IIA. Biochemistry 2008, 47 : $5111-5126$

9. Bresnick AR, Weber DJ, Zimmer DB: S100 proteins in cancer. Nat Rev Cancer 2015, 15:96-109

10. Kriajevska M, Tarabykina S, Bronstein I, Maitland N, Lomonosov M, Hansen K, Georgiev G, Lukanidin E: Metastasis-associated Mts1 (S100A4) protein modulates protein kinase C phosphorylation of the heavy chain of nonmuscle myosin. J Biol Chem 1998, 273:9852-9856

11. Helfman DM, Kim EJ, Lukanidin E, Grigorian M: The metastasis associated protein S100A4: role in tumour progression and metastasis. Br J Cancer 2005, 92:1955-1958

12. Tarabyking S, Griffiths TR, Tulchinsky E, Mellon JK, Bronstein IB, Kriajevska M: Metastasis-associated protein S100A4: spotlight on its role in cell migration. Curr Cancer Drug Targets 2007, 7:217-228

13. Santamaria-Kisiel L, Rintala-Dempsey AC, Shaw GS: Calciumdependent and -independent interactions of the S100 protein family. Biochem J 2006, 296:201-214

14. Newell-Litwa KA, Horwitz R, Lamers ML: Non-muscle myosin II in disease: mechanisms and therapeutic opportunities. Dis Model Mech 2015, 8:1495-1515

15. Ouderkirk JL, Krendel M: Non-muscle myosins in tumor progression, cancer cell invasion and metastasis. Cytoskeleton 2014, 71:447-463

16. Coaxum SD, Tiedeken J, Garrett-Mayer E, Myers J, Rosenzweig SA, Neskey DM: The tumor suppressor capability of p53 is dependent on non-muscle myosin IIA function in head and neck cancer. Oncotarget 2017, 8:22991-23007

17. Tochmoto M, Oguri Y, Hashimura M, Konno R, Matsumoto T, Yokoi A, Kodera Y, Saegusa M: S100A4/non-muscle myosin II signaling regulates epithelial-mesenchymal transition and stemness in uterine carcinosarcoma. Lab Invest 2020, 100:682-695

18. Saegusa M, Hashimura M, Kuwata T, Hamano M, Okayasu I: Crosstalk between NF-KB/p65 and $\beta$-catenin/TCF4/p300 signalling pathways through alterations in GSK- $3 \beta$ expression during trans-differentiation of endometrial carcinoma cells. J Pathol 2007, 213:35-45

19. Saegusa M, Hashimura M, Suzuki E, Yoshida T, Kuwata T: Transcriptional up-regulation of Sox 9 by NF- $\mathrm{BB}$ in endometrial carcinoma cells, modulating cell proliferation through alteration in the $\mathrm{p} 14^{\mathrm{ARF}} / \mathrm{p} 53 / \mathrm{p} 21^{\mathrm{WAF1}}$ pathway. Am J Pathol 2012, 181:684-692
20. Longacre TA, Wells M, Bell DA, Malpica A, Prat J, Ronnet BM: Tumours of the ovary. Edited by Kurman RJ, Carcangiu ML, Herrington CS, Young RH. In WHO Classification of Tumours of Female Reproductive Organs, Fourth Edition. Lyon, France: IARC Publications, 2014. pp. 11-86

21. Yemelyanova A, Vang R, Kshirsagar M, Lu D, Marks MA, Shih LEM, Kurman RJ: Immunohistochemical staining patterns of p53 can serve as a surrogate marker for TP53 mutations in ovarian carcinomas: an immunohistochemical and nucleotide sequencing analysis. Mod Pathol 2011, 24:1248-1253

22. Xie R, Loose DS, Shipley GL, Xie S, Bassett RL Jr, Broaddus RR: Hypomethylation-induced expression of S100A4 in endometrial carcinoma. Mod Pathol 2007, 20:1045-1054

23. Akiya M, Yamazaki M, Matsumoto T, Kawashima Y, Oguri Y, Kajita S, Kijima D, Chiba R, Yokoi A, Takahashi H, Kodera Y, Saegusa M: Identification of LEFTY as a molecular marker for ovarian clear cell carcinoma. Oncotarget 2017, 8:63646-63664

24. Orre LM, Panizza E, Kaminskyy VO, Vernet E, Graslund T, Zhivotovsky B, Lehtio J: S100A4 interacts with p53 in the nucleus and promotes p53 degradation. Oncogene 2013, 32:5531-5540

25. Mani SA, Guo W, Liao MJ, Eaton EN, Ayyanan A, Zhou AY, Brooks M, Reinhard F, Zhang CC, Shipitsin M, Campbell LL, Polyak K, Brisken C, Yang J, Weinberg RA: The epithelialmesenchymal transition generates cells with properties of stem cells. Cell 2008, 133:704-715

26. Ito M, Kizawa K: Expression of calcium-binding S100 proteins A4 and A6 in regions of the epithelial sac associated with the onset of hair follicle regeneration. J Invest Dermatol 2001, 116:956-963

27. Straight AF, Cheung A, Limouze J, Chen I, Westwood NJ, Sellers JR, Mitchison TJ: Dissecting temporal and spatial control of cytokinesis with a myosin II inhibitor. Science 2003, 299:1743-1747

28. Walker A, Su H, Conti MA, Harb N, Adelstein RS, Sato N: Nonmuscle myosin II regulates survival threshold of pluripotent stem cells. Nat Commun 2010, 1:71

29. Rosty C, Ueki T, Argani P, Jansen M, Yeo CJ, Cameron JL, Hruban RH, Goggins M: Overexpression of S100A4 in pancreatic duct adenocarcinomas is associated with poor differentiation and DNA hypomethylation. Am J Pathol 2002, 160:45-50

30. Anon: Integrated genomic analyses of ovarian carcinoma. Nature 2011, 474:609-615

31. Havrilesky L, Darcy KM, Hamdon H, Priore RL, Leon J, Bell J, Berchuck A: Prognostic significance of p53 mutation and p53 overexpression in advanced epithelial ovarian cancer: a gynecologic oncology group study. J Clin Oncol 2003, 21:3814-3825

32. Leitao MM, Soslow RA, Baergen RN, Olvera N, Arroyo C, Boyd J: Mutation and expression of the TP53 gene in early stage epithelial ovarian carcinoma. Gynecol Oncol 2004, 93:301-306

33. Fernandez-Fernandez MR, Veprintsev DR, Fersht AR: Proteins of the C100 family regulate the oligomerization of p53 tumor suppressor. Proc Natl Acad Sci U S A 2005, 102:4735-4740

34. Grigoriant M, Andresen S, Tulchinsky E, Kriajevskya M, Carberg C, Kruse C, Cohn M, Ambartsumian N, Christensen A, Selivanova G, Lukanidin E: Tumor suppressor p53 protein is a new target for the metastasis-associated Mts1/S100A4 protein: functional consequences of their interactions. J Biol Chem 2001, 276:22699-22708

35. Berge G, Maelandsmo GM: Evaluation of potential interactions between the metastasis-associated protein S100A4 and the tumor suppressor protein p53. Amino Acids 2011, 41:863-873

36. Sali A, Glaeser R, Earnest T, Baumeister W: From words to literature in structural proteomics. Nature 2003, 422:216-225

37. Chen H-I, Fernig DG, Rudland PS, Spark A, Wilkinson MC, Barraclough R: Binding to intracellular targets of the metastasisinducing protein, S100A4 (p9Ka). Biochem Biophys Res Commun 2001, 286:1212-1217

38. Li Z-H, Spektor A, Varlamova O, Bresnick AR: Mst1 regulates the assemble of nonmuscle myosin-IIA. Biochemistry 2003, 42: $14258-14266$ 
39. Li Z-H, Bresnick AR: The S100A4 metastasis factor regulates cellular motility via a direct interaction with myosin-IIA. Cancer Res 2006, 66:5173-5180

40. Chow K-H, Park HJ, George J, Yamamoto K, Gallup AD, Graber JH, Chen Y, Jiang W, Steindler DA, Neilson EG, Kim BYS, Yun K: $\mathrm{S} 100 \mathrm{~A} 4$ is a biomarker and regulator of glioma stem cells that is critical for mesenchymal transition in glioblastoma. Cancer Res 2017 , 77:5360-5373

41. Lo J-F, Yu C-C, Chiou S-H, Huang C-Y, Jan C-I, Lin S-C, Liu C-J, Hu W-Y, Yu Y-H: The epithelial-mesenchymal transition mediator S100A4 maintains cancer-initiating cells in head and neck cancers. Cancer Res 2011, 71:1912-1923

42. Mahon PC, Baril P, Bhakta V, Chelala C, Caulee K, Harada T, Lemoine NR: S100A4 contributes to the suppression of BNIP3 expression, chemoresistance, and inhibition of apoptosis in pancreatic cancer. Cancer Res 2007, 67:6786-6795

43. He M, Rennie PS, Gragowska V, Nelson CC, Jia W: A mutant P53 can activate apoptosis through a mechanism distinct from those induced by wild type P53. FEBS 2002, 517:151-154
44. Barrallo-Gimeno A, Nieto MA: The Snail gene as inducers of cell movement and survival: implications in development and cancer. Development 2005, 132:3151-3161

45. Giese A, Loo MA, Tran N, Haskett D, Coons SW, Berens ME: Dichotomy of astrocytoma migration and proliferation. Int J Cancer 1996, 67:275-282

46. Boye K, Malandsmo GM: S100A4 and metastasis: a small actor playing many roles. Am J Pathol 2010, 176:528-535

47. Giese A, Bjerkvig R, Berens ME, Westphal M: Cost of migration invasion of malignant glioma and implications for treatment. J Clin Oncol 2003, 21:1624-1636

48. Merzak A, McCrea S, Koocheckpour S, Pilkington GJ: Control of human glioma cell growth, migration and invasion in vitro by transforming growth factor beta 1. Br J Cancer 1994, 70: 199-203

49. Vang R, Shin 1-M, Kurman RJ: Ovarian low-grade and high-grade serous carcinoma: pathogenesis, clinicopathologic and molecular biologic features, and diagnostic problems. Adv Anat Pathol 2009, $16: 267-282$ 